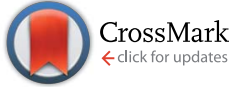

Cite this: RSC Adv., 2017, 7, 7227
Received 24th November 2016 Accepted 13th January 2017

DOI: 10.1039/c6ra27286j

www.rsc.org/advances

\section{Development of a harvesting technique for large- scale microalgal harvesting for biodiesel production}

\begin{abstract}
Shankha Koley, Satyapal Prasad, Sourav Kumar Bagchi and Nirupama Mallick*
Harvesting imposes a major constraint in microalgal downstream processes and cost-effective production of various high value products. In this study, different harvesting techniques were assessed under a single domain to identify the most suitable one for large-scale harvesting of green microalgae for biodiesel purpose. In the laboratory, Scenedesmus obliquus showed a flocculation efficiency of $83.2 \%$ at pH 12 after $1 \mathrm{~h}$. Maximum flocculation efficiencies of 80.2, 95 and 91\%, respectively were observed for $\mathrm{FeCl}_{3}$ at $200 \mathrm{mg} \mathrm{L}^{-1}$, alum at $250 \mathrm{mg} \mathrm{L}^{-1}$ and chitosan at $20 \mathrm{mg} \mathrm{L}^{-1}$ after $1 \mathrm{~h}$. Electro-flotation at $24 \mathrm{~V}$ and dissolved air flotation with $1 \mathrm{mg} \mathrm{L}^{-1}$ of alum also revealed flocculation efficiencies of 99 and $91 \%$ respectively, after $1 \mathrm{~h}$. For Chlorella vulgaris, similar trends were also observed. Under field trials with $1000 \mathrm{~L}$ algal suspension, electro-flotation required a voltage of $60 \mathrm{~V}$ to achieve a flocculation efficiency of $\sim 90 \%$ after $24 \mathrm{~h}$. Dissolved air flotation also showed a flocculation efficiency of same magnitude after $7 \mathrm{~h}$, but with $10 \mathrm{mg} \mathrm{L}^{-1}$ of alum. Thus electro-flotation required a profoundly higher voltage with increasing culture volume, whereas for dissolved air flotation a much higher concentration of alum was entailed. Both the processes also depicted a significantly longer time period to achieve the required flocculation efficiency. On the other hand, $\mathrm{pH}$-induced flocculation was found to be the most pertinent one for large-scale set-ups, and emerged to be efficient, cost-effective and eco-friendly as the supernatant can be reused as growth medium by re-supplementing the nutrients and adjusting the $\mathrm{pH}$.
\end{abstract}

\section{Introduction}

In the current scenario, microalgal lipids have received much attention as a green and renewable resource with the potential to be transesterified to biodiesel, an alternative to the conventional diesel fuel. However, microalgal suspension being very dilute in nature makes the biomass harvesting highly expensive. ${ }^{1}$ The energy requirement for separation of microalgae by centrifugation process can go up to $1 \mathrm{MJ} \mathrm{kg}^{-1}$ of dry biomass. ${ }^{2}$ Report also shows that the harvesting cost of microalgae may go up to $30 \%$ of the total cost of biomass production, ${ }^{3}$ thus playing a major role in the price hike of microalgal products. Therefore, development of a suitable harvesting technique for microalgae carries immense importance, which must be energy efficient, cost-effective and non-polluting in nature.

Microalgal biomass recovery faces many challenges. Due to the low biomass concentration relative to the volume of liquid of algal suspension, which typically varies between 0.3 to $5.0 \mathrm{~g}$ $\mathrm{L}^{-1}$ dry biomass, ${ }^{4,5}$ separation of biomass becomes a highly tedious task. For industrial applications, a high concentration, $300-400 \mathrm{~g} \mathrm{~L} \mathrm{~L}^{-1}$ dry biomass is required, thus requiring

Agricultural and Food Engineering Department, Indian Institute of Technology Kharagpur, Kharagpur-721302, India. E-mail: nm@agfe.iitkgp.ernet.in; Fax: +91 3222 282244; Tel: +913222 283166 a concentration up to 1000 fold. Moreover, the zeta potential of microalgal cells creates a stable suspension. ${ }^{6}$ There are other criteria which are to be considered in harvesting technologies along with the flocculation efficiency and the cost effectiveness. The most important one was the reusability of the culture medium, as it can reduce the water use along with diminishing the cultivation cost.

Various harvesting techniques are practiced these days, viz. centrifugation, filtration, gravity settling, flocculation, etc. Since centrifugation carries a high cost, it is not preferred for large scale installations. ${ }^{7}$ Flocculation has an added advantage over centrifugation as a large volume of cultures can be handled, and is both cost and energy efficient. Flocculation of microalgae can be achieved by the use of various inorganic salts, viz. $\mathrm{Al}_{2}\left(\mathrm{SO}_{4}\right)_{3}$, $\mathrm{AlCl}_{3}, \mathrm{Fe}_{2}\left(\mathrm{SO}_{4}\right)_{3}, \mathrm{FeCl}_{3}, \mathrm{ZnSO}_{4}, \mathrm{ZnCl}_{2}, \mathrm{CaSO}_{4}, \mathrm{CaCl}_{2}, \mathrm{MgSO}_{4}$, $\mathrm{MgCl}_{2},\left(\mathrm{NH}_{4}\right)_{2} \mathrm{SO}_{4}$, and $\mathrm{NH}_{4} \mathrm{Cl},{ }^{8}$ chitosan, ${ }^{9,10}$ cationic starch, ${ }^{11}$ etc. Flocculating microalgal species can also be used effectively to concentrate microalgae which are of non-flocculating in nature. ${ }^{12}$ Moreover, an electrolytic process of microalgal separation has also been found to be highly efficient. ${ }^{13}$ In this process, microalgal surface charges are neutralized as they move towards the anode, thereby allowing the microalgal cells to form aggregates followed by settling to the bottom. In recent years, it has been reported that dissolved air flotation (DAF) can be applied to harvest microalgae more efficiently than other 
settling methods. ${ }^{14}$ In this process, microalgal flocs are formed and are carried upwards with the air bubbles to form a layer at the surface, which can then be sieved out from the top.

A critical perusal of the available literature revealed that in spite of various harvesting techniques studied and are found efficient for laboratory scale cultures, none of those is defined yet for large-scale harvesting of microalgal biomass. Hence, in this investigation, a comparison of various existing harvesting techniques has been carried out with two microalgal species, viz. Scenedesmus obliquus and Chlorella vulgaris to find out an efficient method for microalgal harvesting feasible for largescale exploitation, keeping in mind of non-polluting in nature and cost-effectiveness. This study also considers another most important aspect of the large-scale algal production system, i.e. the reuse of the supernatant after harvesting the microalgal biomass.

\section{Materials and methods}

\subsection{Organisms and culture conditions}

Axenic cultures of two chlorophycean microalgae, Scenedesmus obliquus (Trup.) Kutz. (SAG 276-3a, Gottingen, Germany) and Chlorella vulgaris (A 96, University of Madras, India) were used in the present investigation. The microalgal cultures were grown at $25 \pm 2{ }^{\circ} \mathrm{C}$; the photoperiod was maintained for $14 \mathrm{~h}$ at a light intensity of $75 \mu \mathrm{mol}$ photon $\mathrm{m}^{-2} \mathrm{~s}^{-1}$ photosynthetically active radiation (PAR). Both the microalgae were cultured in the $\mathrm{N} 11$ medium $^{15}$ at $\mathrm{pH}$ 6.8. The $\mathrm{N} 11$ medium constituents were $1.0 \mathrm{~g} \mathrm{~L}^{-1} \mathrm{KNO}_{3}, 0.083 \mathrm{~g} \mathrm{~L}^{-1} \mathrm{Na}_{2} \mathrm{HPO}_{4} \cdot \mathrm{H}_{2} \mathrm{O}, 0.052 \mathrm{~g} \mathrm{~L}^{-1} \mathrm{KH}_{2} \mathrm{PO}_{4}$, $0.05 \mathrm{~g} \mathrm{~L}^{-1} \mathrm{MgSO}_{4} \cdot 7 \mathrm{H}_{2} \mathrm{O}, 0.01 \mathrm{~g} \mathrm{~L}^{-1} \mathrm{CaCl}_{2} \cdot \mathrm{H}_{2} \mathrm{O}, 1 \mathrm{~mL}$ Fe-EDTA stock (10 g chelate per liter) and $1 \mathrm{~mL}$ trace metal mix. The batch cultures were maintained in $250 \mathrm{~mL}$ Erlenmeyer flasks with $100 \mathrm{~mL}$ of $\mathrm{N} 11$ medium. No air or $\mathrm{CO}_{2}$ was sparged to the cultures, and the cultures were hand shook 2-3 times daily to avoid settling. These batch cultures were referred to be control cultures.

For laboratory scale studies, the test microalgae were grown in $4 \mathrm{~L}$ capacity haffkine flasks (maximum working volume: $2 \mathrm{~L}$ ) under the above culture conditions. The experiments were conducted in triplicate. As the age of the cultures plays a major role in flocculation, 20-21 days old cultures were always used for the experiments. Experiments were conducted by transferring the cultures into $1 \mathrm{~L}$ glass cylinders (height $45 \mathrm{~cm}$, Borosil made) maintaining the same optical density (O.D. at $540 \mathrm{~nm}: 1.20 \pm 0.02)$ at the initiation of the experiment. The initial biomass concentration was maintained at $1 \mathrm{~g} \mathrm{~L}^{-1}$. Outdoor large-scale cultivation was carried out in raceway ponds $(14 \times 4 \times 0.75 \mathrm{~m}) .16000 \mathrm{~L}$ culture volume was maintained in each raceway pond at $30 \mathrm{~cm}$ height, and the culture was aerated by the use of mechanical paddle wheels. This was used for large-scale studies. The age of the cultures (20-21 days) was also maintained for large-scale experiments.

\subsection{Flocculation studies at laboratory}

2.2.1. pH-Induced flocculation. Experiments were conducted by the addition of $\mathrm{NaOH}(1 \mathrm{~N})$ and $\mathrm{HCl}(1 \mathrm{~N})$ to adjust the

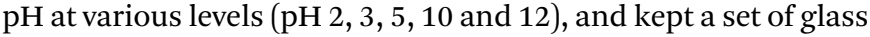
cylinders as control ( $\mathrm{pH}$ 7.0). Following adjustment of $\mathrm{pH}$, each glass cylinder was stirred rapidly at a rpm of 80 for a time duration of $2 \mathrm{~min}$ and with moderate stirring at $20 \mathrm{rpm}$ for a time duration of $30 \mathrm{~min}$. The flocs were left to settle without any agitation for a time period of $30 \mathrm{~min} .{ }^{\mathbf{1 6}}$ The set-up of the experiment was so provided to agitate the whole algal suspension uniformly by placing the stirrer blade at $2.5 \mathrm{~cm}$ from the bottom of the cylinder. After $1 \mathrm{~h}$, the optical densities of the samples were recorded at $540 \mathrm{~nm}$ (this wavelength is not sensitive to change in the culture conditions or absorption shifts $)^{17}$ by cautiously pipetting out samples from the cylinders at $10 \mathrm{~cm}$ height from the bottom. Flocculation efficiency was analysed as described in the later part of this section.

2.2.2. Flocculation by addition of inorganic chemicals. Inorganic compounds (alum and ferric chloride) were used at various concentrations to study their effects on flocculation. The concentrations were varied from a minimum value until the flocculation efficiency became constant. Stock solutions of both the compounds were prepared at a concentration of $10 \mathrm{~g} \mathrm{~L}^{-1}$. Aliquots of algal cultures were taken in $1 \mathrm{~L}$ cylinders, and the flocculants were added accordingly. Concentrations of each flocculant were used in triplicate, and the $\mathrm{pH}$ was maintained at $\mathrm{pH}$ 7.0. The $\mathrm{pH}$ of the solutions was maintained at neutral to observe the effects of the selected inorganic chemicals on flocculation without the influence of the solution $\mathrm{pH}$. Each set of glass cylinders were agitated by the protocol mentioned above. The mixing of the algal samples was found to be necessary, as that will provide uniform mixing of the algal cells with the flocculating agents to form uniform suspension. A control set, without the addition of any flocculants, was also prepared to serve as the reference. Before addition of any flocculant, the optical density of the algal suspension was recorded at $540 \mathrm{~nm}$, and was referred as the initial optical density. As described above, after addition of the flocculant, the solution was vigorously stirred, followed by mild stirring and finally left to settle. Flocculation efficiency was calculated by pipetting out the samples after $1 \mathrm{~h}$, as detailed in the sub section 2.4.

2.2.3. Flocculation by addition of chitosan. The cationic polymer, chitosan was used to study its effect on flocculation. $5 \mathrm{~g}$ of chitosan was dissolved in $500 \mathrm{~mL}$ of acetic acid $(0.1 \mathrm{M})$ followed by mild stirring and heating at about $55{ }^{\circ} \mathrm{C}$ overnight to form $10 \mathrm{~g} \mathrm{~L}^{-1}$ chitosan solution. The stock solution was then added to the experimental vessels at a range of $10-40 \mathrm{mg} \mathrm{L}^{-1}$. As mentioned above, the $\mathrm{pH}$ was maintained at neutral to see the effect of chitosan on flocculation of the test microalgae. The above mentioned flocculation protocol was employed, and the flocculation efficiency was calculated according to the sub section 2.4 .

2.2.4. Dissolved air flotation (DAF). Dissolved air flotation experiments were carried out in glass vessels of dimension $30 \times$ $12 \times 18 \mathrm{~cm}$, containing an algal suspension of $5 \mathrm{~L}$. Two compressor pumps (model: Rocker 320, make: Tarson) were used in these experiments, one for sparging the air and another for sparging the water with/without flocculant (alum) from a plastic jar to the settling tank. Both the pumps were of $1 / 6 \mathrm{hp}$ and had a maximum flow rate of $23 \mathrm{~L} \mathrm{~min}^{-1}$. The flow rate was 
controlled by the help of a controller and the saturation pressure was maintained at 75 psi with a recycle ratio of $15 \%$. The $\mathrm{pH}$ of the experimental sets was normalized to 7.0 before the initiation of the experiments. The sparged air bubbles had a diameter range of $60-150 \mu \mathrm{m}$. The microalgal cells were carried upwards with the air bubbles. The flocculated biomass was sieved out from the top of the glass vessels. Flocculation efficiency was calculated according to the sub section 2.4.

2.2.5. Flocculation by electro-flotation. Electro-flotation experiments were conducted in glass vessels of dimension 60 $\times 30 \times 30 \mathrm{~cm}$, containing an algal suspension of $45 \mathrm{~L}$ from the raceway ponds. The voltage supply was 6,12 and $24 \mathrm{~V}$ through copper and aluminum electrodes, maintaining a current supply of 1.5 A. The copper electrodes acted as cathodes were provided at the bottom of the vessels as meshes, to provide a better surface area for the production of micro bubbles to float the microalgal cells to the top of the vessel. The dimension of the copper mesh was $25 \times 25 \mathrm{~cm}$. The aluminum electrodes were used as anodes, and were placed on both sides of the vessels separated by a distance of $60 \mathrm{~cm}$. Long aluminum pipes with length $30 \mathrm{~cm}$ and diameter $4 \mathrm{~cm}$ were used. The voltage supply was controlled with the help of a DC power supply by connecting the anode to the positive and cathode to the negative terminals of the power supply.

The power consumption was calculated by the formula as given below ${ }^{18}$

$$
E=\frac{U I t}{100 V \eta_{\mathrm{a}} C_{\mathrm{i}}}
$$

where, $U$ is the voltage $(\mathrm{V}), I$ the current (A), $t$ the time of the electroflotation (h), $V$ is the volume of the microalgal suspension $\left(\mathrm{m}^{3}\right), \eta_{\mathrm{a}}$ is the flocculation efficiency, and $C_{\mathrm{i}}$ is the initial biomass concentration $\left(\mathrm{kg} \mathrm{m}^{-3}\right)$.

\subsection{Field-scale study}

From the laboratory-scale experiments, three techniques, i.e. $\mathrm{pH}$-induced flocculation by $\mathrm{NaOH}$, DAF and electro-flotation were selected for field trials.

For field-scale flocculation experiments, $1000 \mathrm{~L}$ tanks were used. The tanks were filled with 20-21 days old $S$. obliquus and C. vulgaris cultures by directly pumping from the raceway ponds. $\mathrm{NaOH}$ solution was added sufficiently to increase the solution $\mathrm{pH}$. The cultures were stirred by the help of a stainless steel stirrer driven by a $0.25 \mathrm{hp}$ motor, Fig. $3 \mathrm{a}$ and $\mathrm{b}$. The tank was fitted with the stirrer in the middle with 3 stainless steel stirrer blades of $30 \mathrm{~cm}$ length. The assembly was attached to the motor with the help of a shaft and were used for stirring. The length of the stirrer blades was so chosen to provide uniform stirring to the whole suspension. The rpm of the motor was controlled by a rpm regulator at $80 \mathrm{rpm}$ for $2 \mathrm{~min}$ and $20 \mathrm{rpm}$ for $30 \mathrm{~min}$. The culture was left to settle for $30 \mathrm{~min}$ and the optical density was recorded. At the beginning of each experiment, the optical density was recorded at $540 \mathrm{~nm}$, and was referred as the initial optical density. To observe the effects of $\mathrm{pH}$ on flocculation, $\mathrm{pH}$ was set to the best value recorded for the laboratory-scale studies.
For electro-flotation experiments, aluminum pipes were placed along the inner surface of the tanks as anodes. The dimension of the aluminum pipes was $90 \mathrm{~cm}$ in length and $4 \mathrm{~cm}$ in diameter. The length of the anode was so chosen that it is immersed completely in the algal solution to provide better electrical conductivity in the solution. The anode to anode distance was $10 \mathrm{~cm}$, and seven aluminum pipes were used as anodes for each tank. Two copper plates of $1000 \mathrm{~cm}^{2}$ were placed at the bottom of each tank to act as cathodes. The large surface area of the copper plates provide better flow of microbubbles. The voltage was varied by a DC power supply (Metravi, India), and the current was maintained at $2 \mathrm{~A}$ (Fig. 4a and b).

Dissolved air flotation was carried out with the help of two compressor pumps of 80 psi pressure (Rockyvac 320, Tarsons, India) for each tank. One pump was connected to the finely perforated air sparger with micro openings for sparging micro bubbles into the experimental tank. The saturation pressure was maintained at $75 \mathrm{psi}$. The other pump was connected to a vessel containing the flocculant. The flocculant was sparged into the tanks slowly. The flocculated microalgae formed a layer at the top of the tank which were sieved out.

\subsection{Determination of flocculation efficiency}

Flocculation efficiency varies with the variation in the sampling height. Therefore, the sampling height was maintained at $10 \mathrm{~cm}$ from the bottom for all sets of experiments. For laboratory-scale studies, the cylinders were graduated with the help of a stainless steel ruler, and $10 \mathrm{~cm}$ height was marked along the side of the cylinders. At different time intervals, an adequate amount of supernatant was pipetted out from the top of the cylinder from the above-mentioned height. For large-scale experiments the sampling height was also maintained at $10 \mathrm{~cm}$. The optical density was recorded in a Lambda 25S UV-VIS spectrophotometer (Perkin Elmer, USA) at a wavelength of $540 \mathrm{~nm}$. The initial as well as all the observations down the time-course of study were recorded. The flocculation efficiency was determined as follows:

$$
\text { Flocculation efficiency }(\%)=(1-A / B) \times 100
$$

where, $A=$ final optical density at $540 \mathrm{~nm}, B=$ initial optical density at $540 \mathrm{~nm}$.

\subsection{Lipid extraction from algal samples}

Bligh and Dyer ${ }^{19}$ protocol using chloroform and methanol as solvents was followed for total lipid extraction from the algal samples (Pl. refer to Mandal and Mallick ${ }^{20}$ for details). Lipid content was expressed as \% dry cell weight (dcw). The weight of the biomass obtained from the control set-up was taken into account for calculating the lipid yield, as the biomass concentration of all setups was approximately same for the experiments. This was to avoid the presence of the flocculants which might interfere in the biomass yield.

To get a clear-cut evidence of various harvesting techniques on lipid recovery, experiments were also conducted in nitrogenand phosphorus-starved cultures, as both the conditions were 
reported to stimulate lipid accumulation in microalgae profoundly. For nitrogen starvation, the test microalgae were grown in the $\mathrm{N} 11$ medium by substituting $\mathrm{KNO}_{3}$ by equimolar concentration of KCl. Similarly, $\mathrm{KH}_{2} \mathrm{PO}_{4}$ and $\mathrm{Na}_{2} \mathrm{HPO}_{4} \cdot \mathrm{H}_{2} \mathrm{O}$ of the medium were substituted by equimolar concentrations of $\mathrm{KCl}$ and $\mathrm{Na}_{2} \mathrm{SO}_{4}$, respectively to achieve P starvation.

\subsection{Nutrients analyses of the supernatant of pH-induced flocculation experiments}

The supernatant obtained after the $\mathrm{pH}$-induced flocculation by $\mathrm{NaOH}$, was siphoned out and the $\mathrm{pH}$ was normalized with the addition of $1 \mathrm{~N} \mathrm{HCl}$. The nutrient concentrations were analyzed using the following protocols. The nitrate concentration was estimated following Nicholas and Nason. ${ }^{21}$ The orthophosphate concentration was measured using the stannous chloride method of APHA. ${ }^{22}$ All other nutrients, viz. potassium, magnesium, sodium, calcium, zinc and copper concentrations were analyzed by Atomic Absorption Spectroscopy (Perkin Elmer A Analyst 800 Atomic Absorption Spectrophotometer, USA). The concentration of sodium was estimated by the use of Ion Chromatography (Metrohm Compact IC Flex Ion Chromatograph, Switzerland). Fresh nutrients were supplemented accordingly to reach the original medium composition. Micronutrients were also re-supplemented, and the growth pattern of both the test microalgae was studied and compared with the growth curves obtained under the original N 11 medium.

\subsection{Statistical analysis}

The reproducibility of the results was checked by repeating the experiments up to three times. Duncan's new multiple range test (DMRT) was used for statistical analysis with MSTAT-C software (Plant and Soil Sciences Division, Michigan State University, USA).

\section{Results and discussion}

\subsection{Harvesting experiments at laboratory scale}

3.1.1. $\mathbf{p H}$-Induced flocculation of microalgae. The flocculation efficiency of the test microalgae was investigated as a function of $\mathrm{pH}$ variation from 2-12. For both the microalgae, $\mathrm{pH}$ range of 10-12 was found to be the most suitable range for flocculation within an hour. For S. obliquus, the maximum flocculation efficiency recorded to be $83.2 \%$ for $\mathrm{pH} 12$ at the end of $1 \mathrm{~h}$, whereas for $\mathrm{pH} 7$, the value was only $17.3 \%$ (Fig. 1a). In $C$. vulgaris, the flocculation efficiency reached up to $65.1 \%$ for $\mathrm{pH}$ 12 and $62.2 \%$ for $\mathrm{pH} 10$ after $1 \mathrm{~h}$ (Fig. 1a). For $\mathrm{pH} 7$, similar to $S$. obliquus, $17 \%$ flocculation efficiency was recorded for $C$. vulgaris. Acidic pHs, except pH 2, did not register considerable flocculation at the early hour of the experiments. Thus, these results depicted that alkaline $\mathrm{pH}$ range was more suitable for harvesting of green microalgae. This was in accordance with the previous report of Wu et al.,$^{23}$ where a $\mathrm{pH}$ range of 10.5-12.5, demonstrated flocculation efficiency of $90 \%$ in two green microalgae, Scenedesmus sp. and C. vulgaris, with a culture density of 0.75 and $0.67 \mathrm{~g} \mathrm{~L}^{-1}$, respectively. The lower flocculation efficiency as observed in this study could be ascribed to

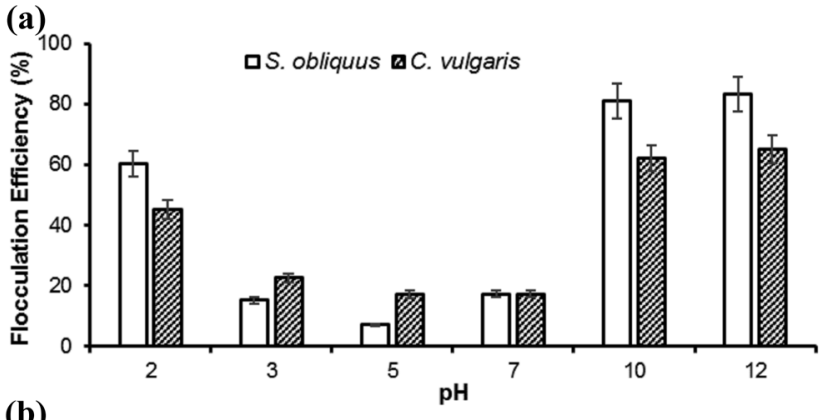

(b)

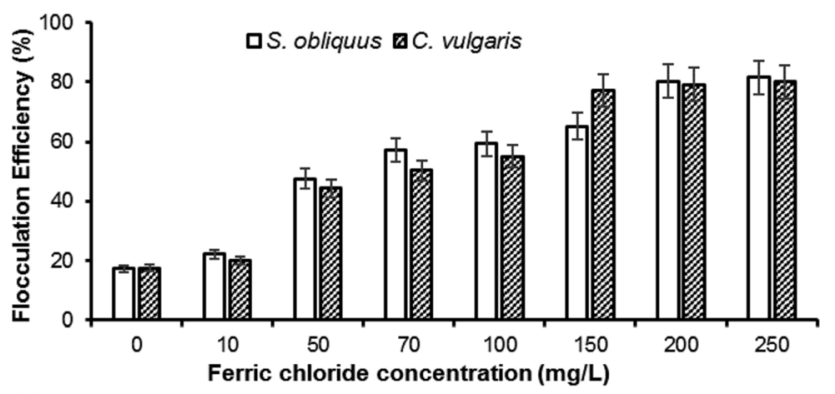

(c)

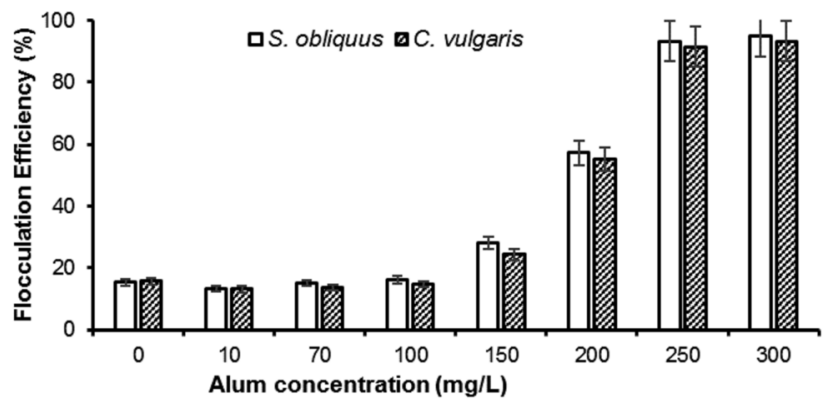

(d)

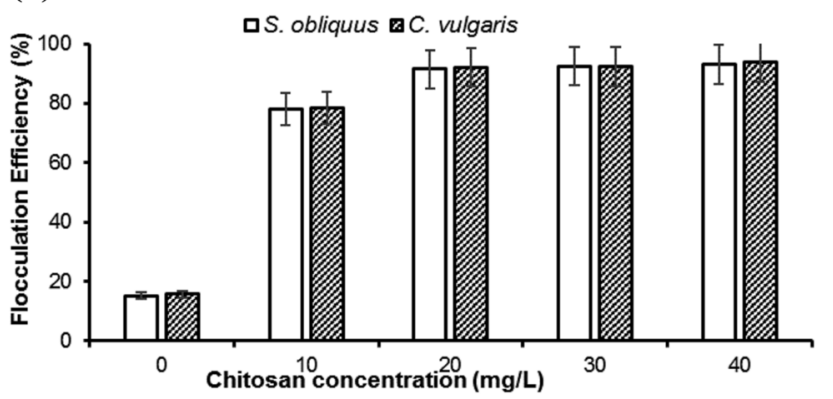

Fig. 1 (a) Flocculation efficiency recorded for S. obliquus and C. vulgaris by variation of $\mathrm{pH}$ after $1 \mathrm{~h}$ under laboratory condition. Number of replicates: 3. (b) Flocculation efficiency recorded for $S$. obliquus and $C$. vulgaris with varied ferric chloride concentrations after $1 \mathrm{~h}$ under laboratory condition. Number of replicates: 3. (c) Flocculation efficiency recorded for $S$. obliquus and $C$. vulgaris with varied alum concentrations after $1 \mathrm{~h}$ under laboratory condition. Number of replicates: 3. (d) Flocculation efficiency recorded for S. obliquus and $C$. vulgaris with varied chitosan concentrations after $1 \mathrm{~h}$ under laboratory condition. Number of replicates: 3 .

the higher biomass concentration $\left(1.0 \mathrm{~g} \mathrm{~L}^{-1}\right)$ taken for the experimentation.

According to Molina et al., ${ }^{24}$ cations played a vital role in flocculation, and the $\mathrm{Mg}^{2+}$ ions present in the medium was 
converted into magnesium hydroxide precipitates at higher $\mathrm{pH}$. Magnesium hydroxide with its positive superficial charges could attract the negative surface charges of microalgae and formed a milky layer coating around the microalgal cells. The loss of negative surface charges did not allow the microalgal cells to repel from each other and flocs were formed. This lead to flocculation and due to the action of gravity settled down to the bottom of the surface. ${ }^{25}$ The difference in flocculation efficiencies in both the microalgal species can be explained by their structural differences, as C. vulgaris cells are unicellular, whereas the S. obliquus cells are joined together in a number of $2-4$. Thus, it can be inferred that the unicellular nature of $C$. vulgaris cells helps them to stay suspended in the medium in a better way than $S$. obliquus.

3.1.2. Flocculation of microalgae by inorganic chemicals. Inorganic chemical flocculation was carried out for the test microalgae by the addition of ferric chloride and alum. The concentrations of ferric chloride were varied from 0 to $250 \mathrm{mg}$ $\mathrm{L}^{-1}$. The $\mathrm{pH}$ of ferric chloride solution was found to be acidic as ferric hydroxide was formed by the combination of ferric ions with hydroxide groups in the solution. Thus, the medium $\mathrm{pH}$ of the experimental setups was adjusted to normal range (pH 7.0). Flocculation efficiency of $80.2 \%$ was recorded after $1 \mathrm{~h}$ at a concentration of $200 \mathrm{mg} \mathrm{L}^{-1}$, and $65.3 \%$ at $150 \mathrm{mg} \mathrm{L}^{-1}$ for $S$. obliquus, whereas the control culture without the addition of ferric chloride depicted a flocculation efficiency of $\sim 17 \%$ only after $1 \mathrm{~h}$ (Fig. 1b). The flocculation efficiency was not found to increase subsequently with the increase in concentration of ferric chloride above $200 \mathrm{mg} \mathrm{L}^{-1}$. Flocculation efficiency for $C$. vulgaris, without the addition of ferric chloride, was found to be $17.5 \%$ after $1 \mathrm{~h}$, whereas 77.2 and $\mathbf{7 9 . 2} \%$ were recorded for 150 and $200 \mathrm{mg} \mathrm{L}^{-1}$ ferric chloride, respectively (Fig. 1b). A recent report of Chatsungnoen and Chisti ${ }^{16}$ depicted a settling rate of $60 \%$ for C. vulgaris by the addition of $200 \mathrm{mg} \mathrm{L}^{-1}$ of ferric chloride, which was increased above $90 \%$ with an increase in the flocculant dose up to $300-500 \mathrm{mg} \mathrm{L}^{-1}$ for a biomass concentration of $1 \mathrm{~g} \mathrm{~L}^{-1}$. At lower biomass concentration of $0.54 \mathrm{~g} \mathrm{~L}^{-1}$, a higher flocculation efficiency $(>90 \%)$ was achieved for the microalga Scenedesmus sp. after $1 \mathrm{~h}$ with a flocculant dosage of $150 \mathrm{mg} \mathrm{L}^{-1} .{ }^{26}$ Thus, higher concentrations of ferric chloride are required for obtaining higher flocculation efficiency for higher biomass concentrations. One earlier report also showed that Chlorella zofingiensis cells were around 10 times larger than the precipitates of ferric hydroxide. ${ }^{27}$ C. vulgaris and S. obliquus are in the range of $5-20 \mu \mathrm{m} .{ }^{28}$ Thus, the positively charged precipitates get attracted to the negatively charged microalgal cells. The ferric hydroxide precipitates are much smaller in comparison to the microalgal cells, which did not meet the requisite to completely cover the microalgal cells at lower doses. This reason became the prime cause for the requirement of sufficient amount of ferric hydroxide in the solution. Thus higher flocculation efficiency was observed with the increase in ferric chloride concentration.

Alum concentration was varied from 0 to $300 \mathrm{mg} \mathrm{L}^{-1}$. The flocculation efficiency reached above $90 \%$ at $250 \mathrm{mg} \mathrm{L}^{-1}$ of alum after $1 \mathrm{~h}$ for both the test microalgae (Fig. 1c). Chen et al. ${ }^{26}$ recorded a flocculation efficiency $93 \%$ with $300 \mathrm{mg} \mathrm{L}^{-1}$ alum for the microalga Scenedesmus sp. Earlier report also depicted that at a lower biomass concentration of $0.25 \mathrm{~g} \mathrm{~L}^{-1}$ with a flocculant dose of $115 \mathrm{mg} \mathrm{L}^{-1}$ alum, 85\% flocculation efficiency was achieved for the same microalga. ${ }^{29}$ The mechanism of flocculation by the alum is that aluminum hydroxide is formed while adding alum to the medium. The positively charged aluminum ions cause neutralization of surface (negative) charges of algae, which brings the individual cells to come together to form flocs, and thus settle down to the bottom. ${ }^{30}$

3.1.3. Flocculation by chitosan. In both the microalgae, $\sim 90 \%$ flocculation efficiency was recorded after $1 \mathrm{~h}$ for 20 $40 \mathrm{mg} \mathrm{L}^{-1}$ of chitosan (Fig. 1d). Whereas, the flocculation efficiency of the control samples of S. obliquus, i.e. without addition of any flocculant was very low; it was observed to be around $15 \%$ after $1 \mathrm{~h}$. For C. vulgaris, $15.7 \%$ flocculation efficiency was recorded at the end of $1 \mathrm{~h}$ for control setups. The mechanism occurring in chitosan flocculation may be likely due to static patch effects with partial charge neutralization. With the addition to reducing or neutralizing the negative surface charge on microalgal cells, the polymer flocculants can also bring the microalgal cells together by physically linking one or more cells through a process called bridging. ${ }^{3,31} \mathrm{Xu}$ et al. ${ }^{32}$ reported that $10 \mathrm{mg} \mathrm{L}^{-1}$ chitosan can exhibit $90 \%$ flocculation in Chlorella sorokiniana at $\mathrm{pH} 7$ with a biomass density of $1 \mathrm{~g} \mathrm{~L}^{-1}$. However, a significantly higher concentration $\left(80 \mathrm{mg} \mathrm{L}^{-1}\right)$ of chitosan requirement was observed for Scenedesmus sp. ${ }^{26}$ In another report, $20 \mathrm{mg} \mathrm{L}^{-1}$ chitosan concentration induced a flocculation efficiency of more than $90 \%$ in Chlorella vulgaris with a lower biomass density of $0.25 \mathrm{mg} \mathrm{L}^{-1}$. $^{29}$ Therefore, in addition to biomass concentration, species/strain-specific response could be the possible reason for these variations. The biomass concentration and molecular weight of the polymers plays a major role in the flocculation process as the higher biomass concentration will accelerate the cell-cell encounters in concentrated suspensions. The higher molecular weight polymers are more efficient due to their better bridging abilities. ${ }^{3}$

3.1.4. Dissolved air flotation. Dissolved air flotation was carried out on both the microlagal species with/without alum, since it was reported that addition of coagulants increased the flocculation efficiency. ${ }^{33}$ The hypothesis behind this is that high pressure sparging of flocculant helps in the formation of algal flocs quickly, which are then carried upward by the air bubbles. The flocculation efficiency reached up to $90 \%$ after $1 \mathrm{~h}$ with alum concentration of $1 \mathrm{mg} \mathrm{L}^{-1}$ (Fig. 2). Contrary to this, DAF without alum seemed to be inefficient as in both the cases a maximum of $25 \%$ flocculation efficiency was recorded even after $1.5 \mathrm{~h}$. Zhang et $a .^{34}$ reported that harvesting efficiency become very high for Chlorella zofingiensis with an increase in $\mathrm{Al}^{3+}$ concentration, and $\sim 90 \%$ flocculation efficiency was achieved with $10 \mathrm{mg} \mathrm{g}^{-1} \mathrm{Al}^{3+}$ concentration only after $10 \mathrm{~min}$. The addition of coagulants helps in forming larger flocs and better attachment with the generated microbubbles, which is not possible without the addition of coagulants, as both the bubbles as well as the microalgal cells tend to have negative surface charge. The difference in flocculants doses was clearly evident in this study as $1 \mathrm{mg} \mathrm{g}^{-1}$ alum concentration was sufficient to achieve $90 \%$ flocculation, albeit with an increased time duration of $1 \mathrm{~h}$. 


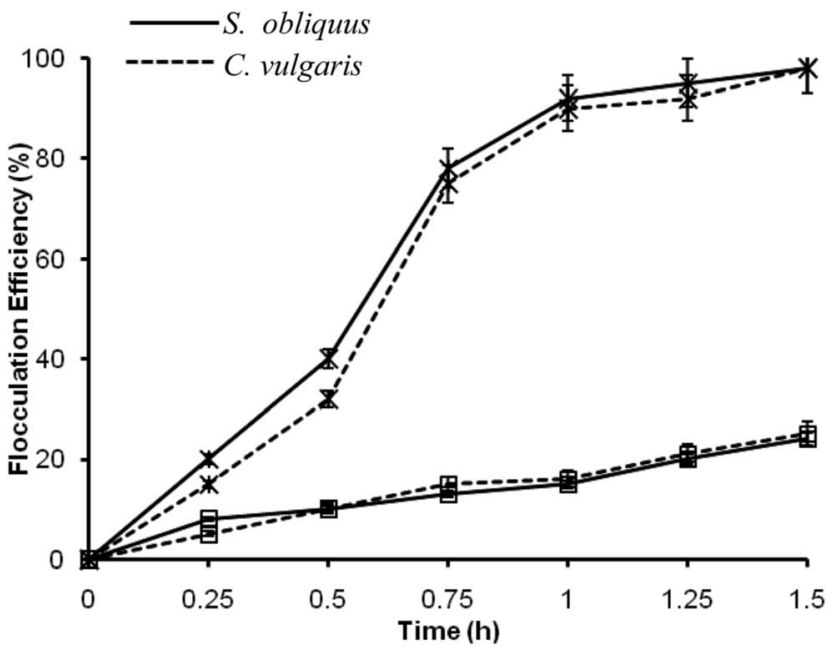

Fig. 2 Flocculation efficiency recorded for S. obliquus and C. vulgaris by dissolved air flotation with and without alum under laboratory condition. $\times$ represents with alum $\left(1 \mathrm{mg} \mathrm{L}^{-1}\right)$ and $\square$ represents without alum. Number of replicates: 3 .

3.1.5. Electro-flotation. Electro-flotation was carried out on both the microalgal species at 6,12 and $24 \mathrm{~V}$. A pictorial view of electro-flotation set-up in the laboratory showing flocculation of S. obliquus at the initiation of experiment and after $1 \mathrm{~h}$, is shown in the Fig. $3 \mathrm{a}$ and $\mathrm{b}$. The flocculation efficiency was seen to vary subsequently with the variation in DC voltage. 95\% flocculation efficiency was observed for $S$. obliquus at $24 \mathrm{~V}$ after a retention time $45 \mathrm{~min}$. This was only 7.5 and $42 \%$, respectively for 6 and 12 V. 99\% flocculation efficiency was achieved after $1 \mathrm{~h}$ retention time with an application of $24 \mathrm{~V}$ (Fig. 3c). The flocculation efficiency was seen to follow the same trend in both the microalgal species, but with a marginally lower value for $C$. vulgaris. The voltage supplied to the electrochemical system determines the charge amount that is to be released from the electrodes. The increase in voltage value imposed into the system leads to faster electrolysis which in turn enhances the electrolysis process, leading to generation of more microbubbles which drives the flotation of microalgal flocs. ${ }^{35}$ The flocculation efficiency of the microalgae depends on applied electricity and also on the microalgal conductivity. ${ }^{29}$ Misra et $a l .{ }^{13}$ observed a flocculation efficiency of $65 \%$ with $8.9 \mathrm{~V}$ for $S$. obliquus cultures. Recently, Zhou et al., ${ }^{35}$ demonstrated that 4$6 \mathrm{~V}$ can exhibit a flocculation efficiency of more than $90 \%$ in Chlorella sp. depending on the culture condition and electrode distance.

3.1.6. Lipid recovery with different harvesting techniques. Lipid content was analyzed from the harvested microalgal biomass obtained with various harvesting techniques for control, $\mathrm{N}$ - and P-starved cultures. It was apparent from Table 1 that the above harvesting techniques had no remarkable effects on the lipid content of both the microalgal species. The possible reason could be that the microalgal cells might not be affected notably during this short exposure to the applied processes.

3.1.7. Comparison of various harvesting techniques studied under laboratory scale. The harvesting techniques (a)

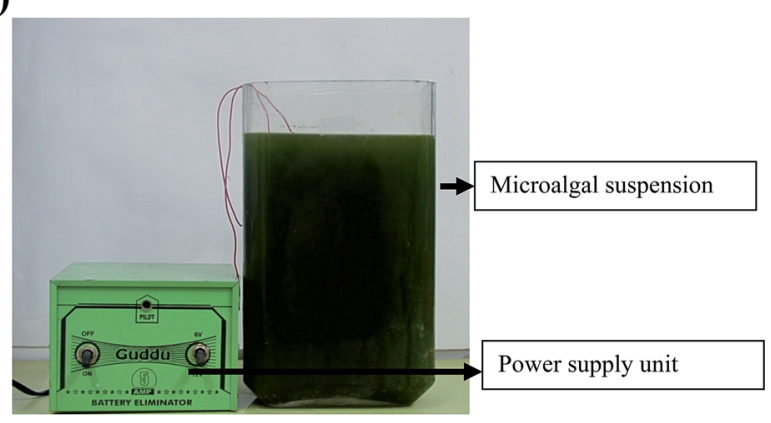

(b)

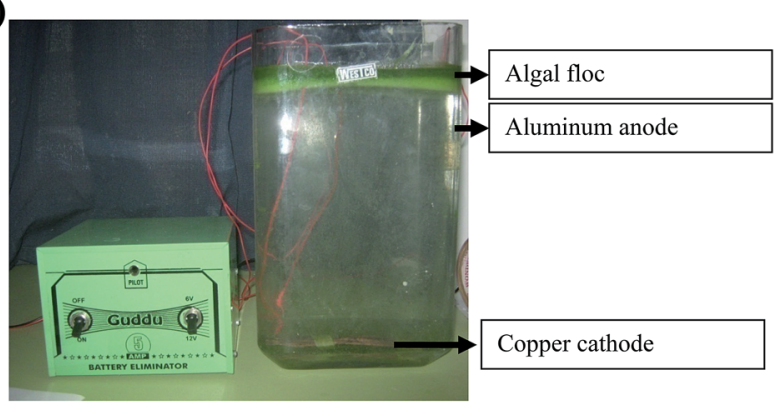

(c)

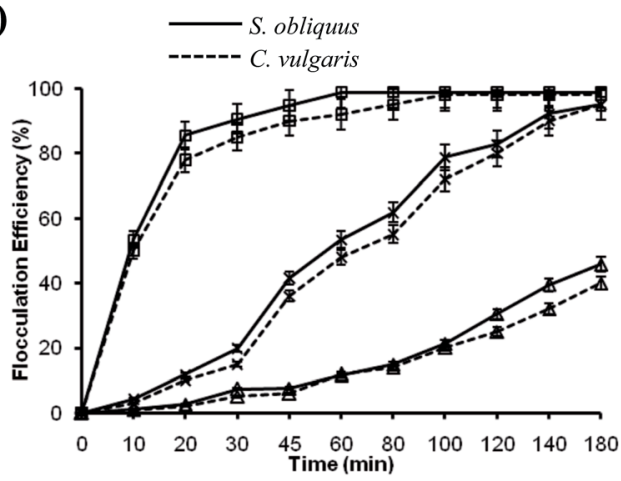

Fig. 3 Electro-flotation set-up in the laboratory showing flocculation of $S$. obliquus (a) at the initiation of experiment and (b) after $1 \mathrm{~h}$. (c) Flocculation efficiency recorded for $S$. obliquus and $C$. vulgaris by electro-flotation under laboratory condition. $\square: 24 \mathrm{~V}, \times: 12 \mathrm{~V}$, and $\triangle$ : $6 \mathrm{~V}$. Number of replicates: 3.

studied in the laboratory scale were performed with various levels of flocculation concentration and its effect on microalgal harvesting was observed. The harvested microalgae were further processed to see the effect of harvesting conditions on the end product i.e. lipid yield. The effect of starvation conditions was also performed to see the outcome on the lipid yield from the microalgal strains. The harvesting techniques were compared based on the results of flocculation efficiency, economic sustainability and their effects on lipid yield.

Table 2 compares the flocculation efficiency, flocculant dose/ $\mathrm{kg}$ harvested biomass, and the costs incurred with different techniques. In case of ferric chloride and alum, although the flocculation efficiency was found to be high enough and the flocculants bulk prices were notably low, the required doses were profoundly high. Thus, with the high concentrations of ferric chloride and alum, the nutritive value of the supernatant (medium) was essentially lost. Moreover, the use of such high 
Table 1 Lipid recovery with respect to various harvesting techniques under laboratory scale studies ${ }^{a}$

\begin{tabular}{|c|c|c|c|c|c|}
\hline $\begin{array}{l}\text { Name of the } \\
\text { microalga }\end{array}$ & Method & Condition & \multicolumn{3}{|c|}{ Lipid content ${ }^{b}(\% \mathrm{dcw})$} \\
\hline & pH-Induced flocculation by $\mathrm{NaOH}$ & pH 12 & $11.62 \pm 0.89^{a}$ & $40.81 \pm 3.02^{a}$ & $28.35 \pm 28.21^{a}$ \\
\hline & $\mathrm{FeCl}_{3}$-induced flocculation & $200 \mathrm{mg} \mathrm{L}^{-1}$ & $11.52 \pm 1.15^{a}$ & $41.23 \pm 4.14^{a}$ & $29.15 \pm 2.25^{a}$ \\
\hline & Alum-induced flocculation & $250 \mathrm{mg} \mathrm{L}^{-1}$ & $10.93 \pm 0.91^{a}$ & $40.51 \pm 3.08^{a}$ & $28.92 \pm 2.31^{a}$ \\
\hline & & Without alum & $10.82 \pm 1.32^{a}$ & $41.63 \pm 3.20^{a}$ & $30.13 \pm 2.14^{a}$ \\
\hline & Electro-flotation & $24 \mathrm{~V}$ & $10.52 \pm 1.41^{a}$ & $41.53 \pm 3.41^{a}$ & $28.41 \pm 2.24^{a}$ \\
\hline \multirow[t]{4}{*}{ C. vulgaris } & Control & N 11 medium & $12.13 \pm 1.32^{a}$ & $42.14 \pm 3.25^{a}$ & $31.72 \pm 2.26^{a}$ \\
\hline & pH-Induced flocculation by $\mathrm{NaOH}$ & pH 12 & $12.44 \pm 1.32^{a}$ & $42.13 \pm 3.12^{a}$ & $32.13 \pm 2.27^{a}$ \\
\hline & $\mathrm{FeCl}_{3}$-induced flocculation & $150 \mathrm{mg} \mathrm{L}^{-1}$ & $12.14 \pm 1.21^{a}$ & $42.91 \pm 3.45^{a}$ & $32.40 \pm 2.35^{a}$ \\
\hline & Alum-induced flocculation & $250 \mathrm{mg} \mathrm{L}^{-1}$ & $12.21 \pm 1.14^{a}$ & $41.50 \pm 3.31^{a}$ & $31.91 \pm 2.42^{a}$ \\
\hline
\end{tabular}

${ }^{a}$ Note: values are means \pm standard deviations of three independent observations. Values superscripted by 'a' symbolize they are not significantly different from each other $(P>0.05$, DMRT). For all the processes the maxima values were considered. Separate analysis was done for each column and each microalga. ${ }^{b}$ Total lipids were extracted after completion of $1 \mathrm{~h}$ of different flocculation experiments.

Table 2 Comparison of flocculation efficiency, flocculant dose/kg harvested biomass and the costs for the two test microalgae under laboratory scale study

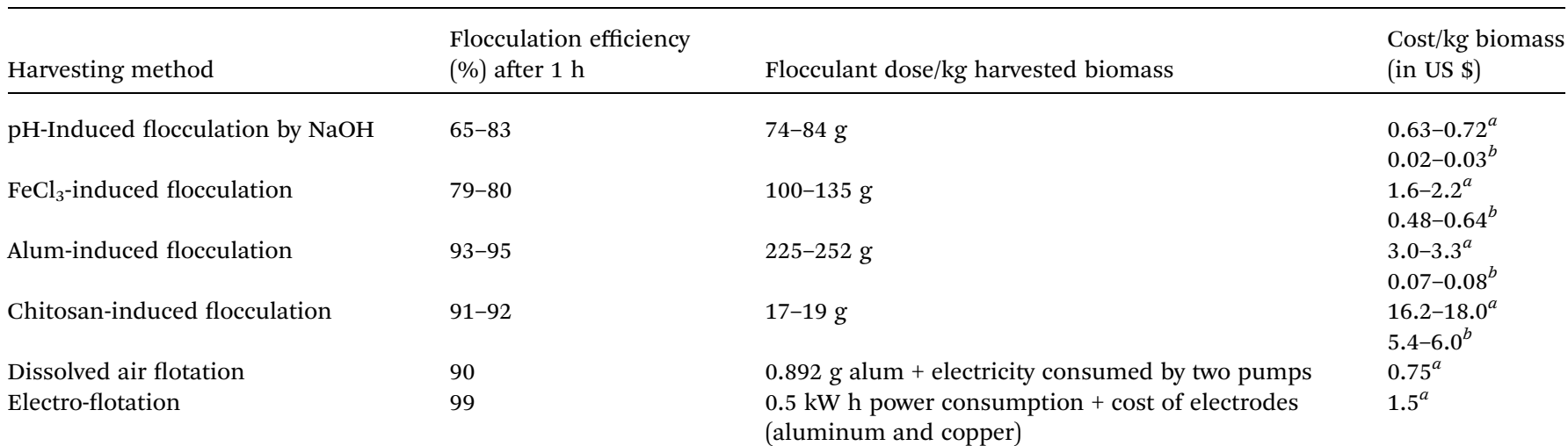

${ }^{a}$ Costs of laboratory grade chemicals (HiMedia Biosciences and Laboratory Chemicals Catalogue, India, 2015-16). ${ }^{b}$ Costs of bulk purchase (http:// www.alibaba.com).

concentrations of inorganic chemicals was not environment friendly, thus made them incongruous for large-scale operation. With chitosan, high flocculation efficiency was also recorded. However, the price of this cationic polymer was found to be considerably high ( $1 \mathrm{~g}$ of chitosan costs 2 US $\$$, HiMedia Bioscience \& Laboratory Chemicals, India; bulk price of chitosan was 300 US \$ for $1 \mathrm{~kg}$, http://www.alibaba.com), and therefore, it would increase the cost of harvesting significantly, thus seems to be not a feasible approach for large-scale operation.

In case of DAF, the flocculation efficiency was also recorded to be high. Furthermore, the amount of alum used was relatively less in quantity. Therefore, the discarded medium (supernatant) with low alum concentration can be reused, which needs further examination. Electro-flotation also showed profoundly high flocculation efficiency, and had no negative impact on lipid recovery. In the case of $\mathrm{pH}$-induced flocculation by $\mathrm{NaOH}$, the flocculation efficiency was found to be comparatively low. However, the supernatant can be reused for microalgal cultivation after $\mathrm{pH}$ neutralization and nutrient re-supplementation, which would ultimately lead to a decrease in the production cost. It is also apparent from Table 2 that the cost of harvesting was the lowest for the $\mathrm{pH}$-induced flocculation by $\mathrm{NaOH}$. Hence, the above three techniques ( $\mathrm{pH}$-induced flocculation by $\mathrm{NaOH}, \mathrm{DAF}$ and electro-flotation) were checked further at field level.

\subsection{Harvesting experiments at field-scale}

Although many researchers, nowadays, are focusing their attention to combat the problem of microalgal harvesting for 
low-cost biofuel production, ${ }^{\mathbf{1 6}, \mathbf{3 6}-\mathbf{3 8}}$ a technique feasible for largescale application is yet be comprehended. Therefore, there is a need to see the performance of the above selected flocculation techniques at field level.

3.2.1. pH-Induced flocculation by $\mathrm{NaOH}$. pH-Induced flocculation by $\mathrm{NaOH}$ was carried out in $1000 \mathrm{~L}$ tanks at $\mathrm{pH}$ 12. A pictorial view of flocculation of $S$. obliquus in a $1000 \mathrm{~L}$ tank is presented in the Fig. $4 \mathrm{a}$ and b. About $75 \%$ flocculation efficiency was recorded for $S$. obliquus after $1 \mathrm{~h}$, and for $C$. vulgaris, the flocculation efficiency was $\sim 60 \%$, Fig. $4 \mathrm{c}$, which was consistent with the results obtained for laboratory scale study. Thus, it can be concluded that $\mathrm{pH}$-induced flocculation by $\mathrm{NaOH}$ can be used to harvest microalgae from large-scale setups.

3.2.2. Flocculation by electro-flotation. Electro-flotation experiments at field-scale were carried out by using copper and aluminum electrodes. Aluminum pipes were attached to the inner wall of the $1000 \mathrm{~L}$ tank and acted as anodes. Two copper plates of $1 \mathrm{ft}^{2}$ area were placed in the bottom and acted as cathodes. A pictorial view of the set-up is provided in the Fig. 5a and b. Electro-flotation was found to be highly efficient at $24 \mathrm{~V}$ in the laboratory scale experiments. In the field scale setup of $1000 \mathrm{~L}, 24 \mathrm{~V}$ was not found adequate as only $\sim 50 \%$ flocculation was observed after $24 \mathrm{~h}$ (Fig. 5c). With an increase in the voltage to $60 \mathrm{~V},>90 \%$ flocculation was achieved after $24 \mathrm{~h}$ for both the test microalgae. At the first hour of the experiment, only $48-50 \%$ flocculation was recorded. The flocculation efficiency depends upon the applied voltage as well as the microalgal conductivity, thus the requirement of voltage and time were found to increase with the increasing volume of cultures. The voltage required was more to generate more microbubbles on a large surface area and consecutively to float the microalgal cells to the top. ${ }^{35}$ Following these reasons, due to increased power consumption with the increase in the volume of cultures, this method was not found to be feasible for large-scale harvesting.

3.2.3. Dissolved air floatation. Dissolved air flotation was carried out with varying alum concentration from of 1.0 to $10 \mathrm{mg} \mathrm{L^{-1 }}$ (Fig. 6). 90\% flocculation efficiency was achieved after $7 \mathrm{~h}$ with $10 \mathrm{mg} \mathrm{L}^{-1}$ alum for $S$. obliquus. Contrary to the laboratory scale study, flocculation efficiency achieved with $1 \mathrm{mg} \mathrm{L}^{-1}$ alum concentration in $1000 \mathrm{~L}$ tanks was only $40 \%$ at the end of $7 \mathrm{~h}$. Thus, the alum concentration required at field scale was much higher than the laboratory scale set-ups of $1 \mathrm{mg}$ $\mathrm{L}^{-1}$ only, which indicates the need for more alum with increase in the volume of cultures. The quantity of alum increased as floc formation was not adequate enough in lower doses and the efficiency decreased. The floc should be large enough to get attached to the air bubbles to float up to the surface. The higher recycle ratio of $15 \%$ helped in producing better micro bubble formation which increased the efficiency with increase in coagulant doses. The flocculation time was also found to rise significantly. C. vulgaris also followed a similar pattern (data not shown).

3.2.4. Reuse of the supernatant from $\mathbf{p H}$-induced flocculation by $\mathrm{NaOH}$. $\mathrm{pH}$-Induced flocculation by $\mathrm{NaOH}$ was found to be efficient for microalgal harvesting. Thus, the supernatant, after adjusting the $\mathrm{pH}$ and re-supplementing nutrients, was explored to be reused as growth medium. Table 3 depicts the concentrations of the essential nutrients in the supernatant after harvesting. Accordingly, the adjusted medium was resupplemented with the required essential nutrients. The concentration of sodium was found to be in the same range before and after harvesting due to the use of $\mathrm{NaOH}$ to reach $\mathrm{pH}$

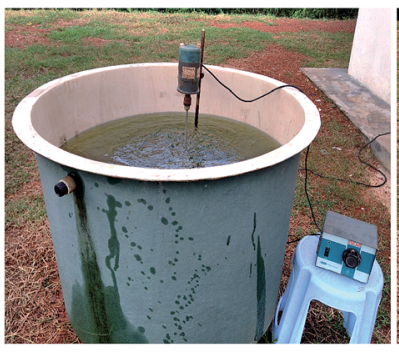

(a)

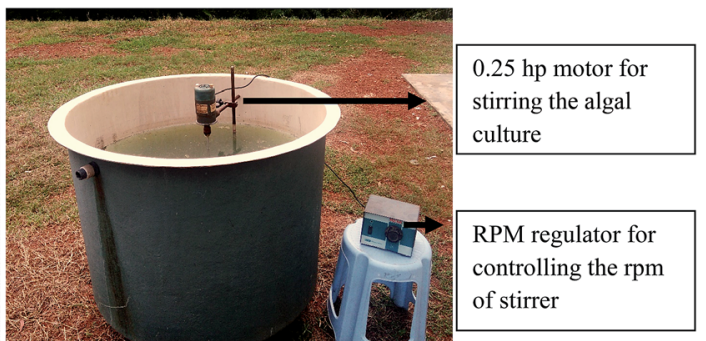

(b)

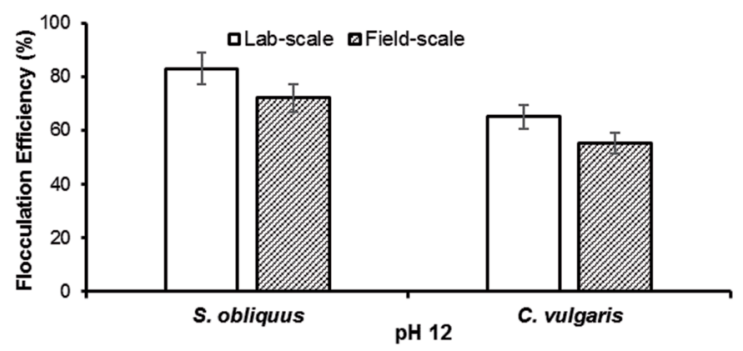

(c)

Fig. $4 \mathrm{pH}$-Induced flocculation at $\mathrm{pH} 12$ set-up in $1000 \mathrm{~L}$ tank showing flocculation of S. obliquus (a) at the initiation of experiment and (b) after $1 \mathrm{~h}$. (c) Flocculation efficiency recorded for S. obliquus and C. vulgaris at $\mathrm{pH} 12$ after $1 \mathrm{~h}$ under field scale. Number of replicates: 3. 
(a)

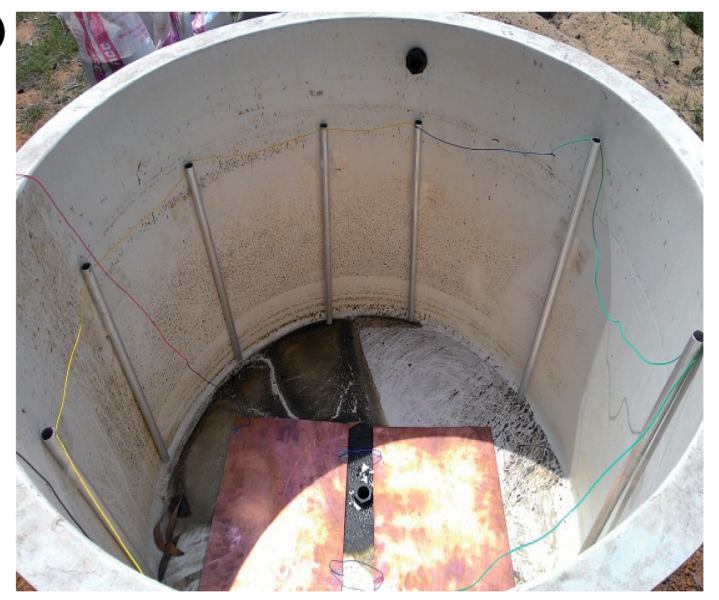

(b)

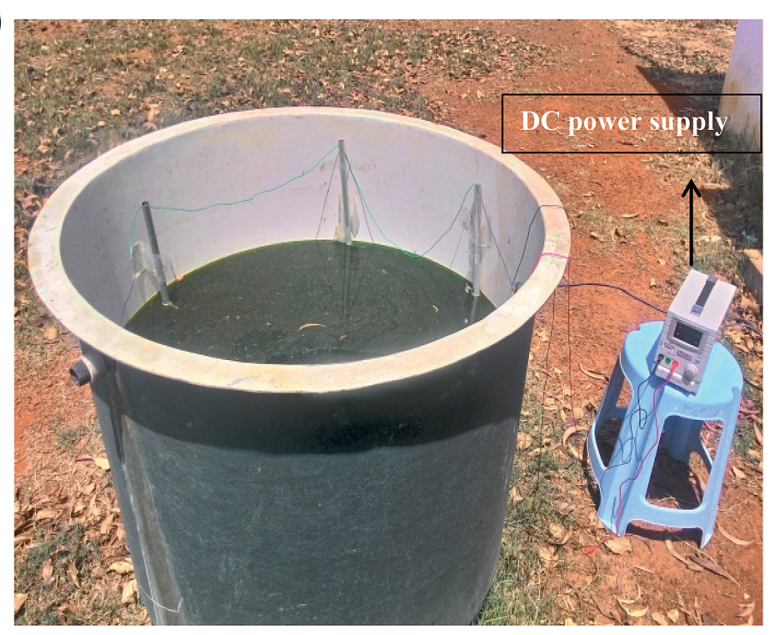

(c)

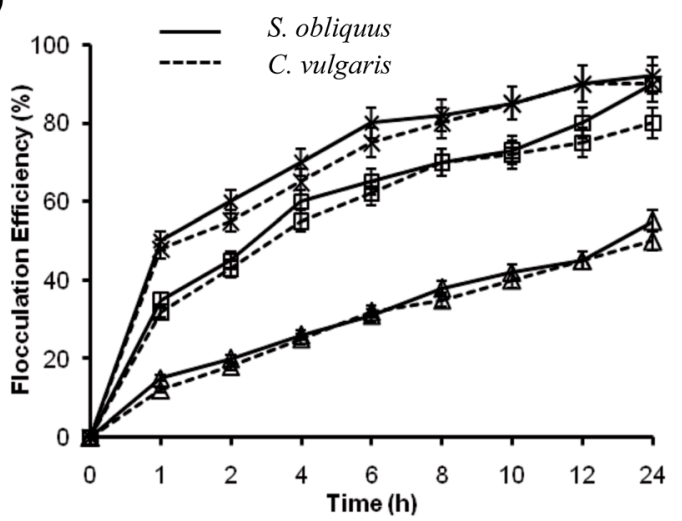

Fig. 5 (a) Set-up for electro-flotation. $1000 \mathrm{~L}$ tanks with hollow aluminium pipes as anode attached to the inner wall of the tank. Two copper plates of $1000 \mathrm{~cm}^{2}$ each were used as cathodes. (b) Flocculated microalgae by electro-flotation. (c) Flocculation efficiency recorded for $S$. obliquus and $C$. vulgaris by electro-flotation at field scale. $\times$ represents $60 \mathrm{~V}, \square$ represents $48 \mathrm{~V}$, and $\Delta$ represents $24 \mathrm{~V}$. Number of replicates: 3 .

12. This is also a major advantage of the use of $\mathrm{NaOH}$ with respect to other flocculation methods. The time-course study (Fig. 7) depicted that the growth pattern in the fresh $\mathrm{N} 11$ medium and the adjusted medium (supernatant obtained from the $\mathrm{pH}$-induced flocculation experiments, $\mathrm{pH}$ normalised and

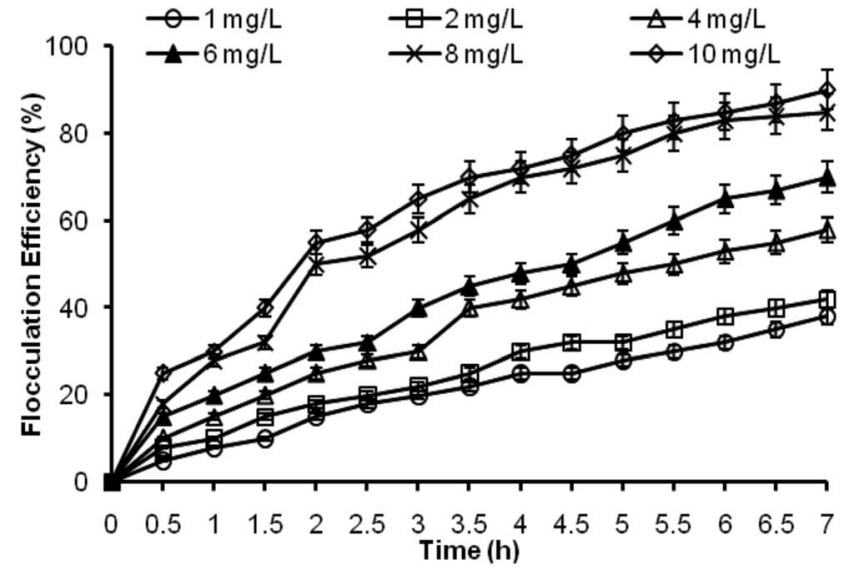

Fig. 6 Flocculation efficiency recorded for S. obliquus by dissolved air flotation with various alum concentrations in field scale studies. Number of replicates: 3 .

Table 3 Concentration of essential nutrients in the medium before cultivation and after harvesting $^{a}$

\begin{tabular}{lcc}
\hline $\begin{array}{l}\text { Essential nutrients } \\
\text { in the medium }\end{array}$ & $\begin{array}{l}\text { Concentration before } \\
\text { cultivation }\left(\mathrm{mg} \mathrm{L}^{-1}\right)\end{array}$ & $\begin{array}{c}\text { Concentration in the } \\
\text { supernatant }\left(\mathrm{mg} \mathrm{L}^{-1}\right)\end{array}$ \\
\hline Potassium & $412.21 \pm 10.10$ & $102.14 \pm 8.10$ \\
Sodium & $27.14 \pm 1.10$ & $32.24 \pm 1.30$ \\
Nitrate & $595.12 \pm 13.10$ & $89.08 \pm 4.41$ \\
Phosphate & $102.04 \pm 6.20$ & $53.15 \pm 5.20$ \\
Magnesium & $4.91 \pm 0.79$ & $2.96 \pm 0.84$ \\
Iron & $0.21 \pm 0.01$ & $0.10 \pm 0.02$ \\
Copper & $0.021 \pm 0.001$ & $0.011 \pm 0.001$ \\
Zinc & $0.49 \pm 0.05$ & $0.060 \pm 0.003$ \\
${ }^{a}$ Number of replicates: 3. &
\end{tabular}

nutrient re-supplemented) was comparable. This finding was also supported by the earlier work of Wu et al. ${ }^{23}$ and Kim et al. ${ }^{39}$ where reuse of the flocculated medium was advocated after

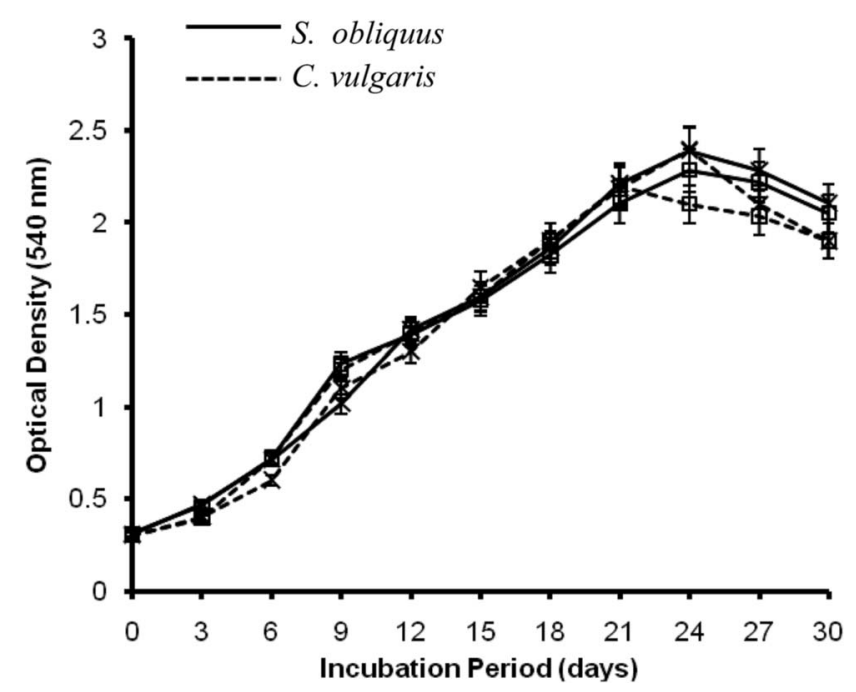

Fig. 7 Comparative growth curves of S. obliquus and C. vulgaris in N 11 and the adjusted media. $\times$ represents $N 11$ (control) and $\square$ represents $\mathrm{pH}$ and nutrients adjusted medium. Number of replicates: 3 . 
Table 4 Comparison of flocculation efficiency, flocculant dose/kg harvested biomass and costs under field scale study

\begin{tabular}{llll}
\hline Harvesting methods & $\begin{array}{l}\text { Flocculation efficiency } \\
(\%) \text { after } 1 \mathrm{~h}\end{array}$ & Flocculant dose/kg harvested biomass & $\begin{array}{l}\text { Cost/kg biomass } \\
\text { (in US \$) }\end{array}$ \\
\hline $\begin{array}{l}\text { pH-Induced flocculation } \\
\text { by NaOH }\end{array}$ & $60-75$ & $50-62 \mathrm{~g} \mathrm{NaOH}+0.2 \mathrm{~kW}$ h power consumption & $\begin{array}{l}0.50-0.53^{a} \\
0.04-0.05^{b} \\
1.05-1.28^{a} \\
0.886-0.888^{b}\end{array}$ \\
$\begin{array}{l}\text { Dissolved air flotation } \\
\begin{array}{l}\text { Electro-flotation } \\
6.31-6.84^{a}\end{array}\end{array}$ & $30-35 \mathrm{~g} \mathrm{alum}+$ electricity consumed by two pumps \\
$\begin{array}{l}\text { a Costs of laboratory grade chemicals (HiMedia Biosciences and Laboratory Chemicals Catalogue, India, 2015-16). }{ }^{b} \text { Costs of bulk purchase (http:// } \\
\text { www.alibaba.com). }\end{array}$
\end{tabular}

harvesting of the algal biomass by $\mathrm{pH}$ increase and/or with the use of bioflocculant, respectively. The nutrient concentrations of the medium were rechecked after every fresh inoculation of algal culture. The culture medium was not reused after three consecutive re-supplementations, and a fresh culture medium was prepared for microlagal cultivation, since after three consecutive uses fouling smell from the medium was sensed.

3.2.5. Comparison of the selected harvesting techniques studied at field scale. The large-scale harvesting techniques were compared on the basis of economic sustainability and the effect on lipid productivity. Large-scale microalgal cultures deal with a large volume and economy plays a major role in the selection of the harvesting technique. Table 4 presents a comparison of flocculation efficiency, costs as well as the flocculant dose $/ \mathrm{kg}$ harvested microalgal biomass, under fieldscale study. Interestingly, the $\mathrm{pH}$-induced flocculation by $\mathrm{NaOH}$ showed a reduction in cost as compared to the laboratory scale study, since less $\mathrm{NaOH}$ was required to raise the $\mathrm{pH}$ of the cultures to $\mathrm{pH} 12$. This is because the $\mathrm{pH}$ of the raceway pond cultures reached high enough up to $\mathrm{pH} 9.5$ after 20-21 days. On the contrary, a tremendous rise in cost was seen for electroflotation. An increase in cost was also recorded for DAF. Further, the requirement of alum was found to increase with the volume of cultures, which will lead to rise in aluminium ions in the medium. Since aluminium is a toxic heavy metal, so it is undesirable in the growth medium for microalgae cultivation. Conversely, the rise in the concentration of $\mathrm{Na}$ ions in the medium in case of $\mathrm{pH}$-induced flocculation by $\mathrm{NaOH}$ is desirable as sodium is a major nutrient for microalgal growth. Moreover, the cost of the process is also found to be the lowest as compared to the other methods. Thus from this study it can be concluded that $\mathrm{pH}$-induced flocculation by $\mathrm{NaOH}$, microlagal harvesting can be conducted at a much lower cost and efficiently in large-scale set-ups.

\section{Conclusion}

Various harvesting techniques were assessed under a single domain for efficient recovery of microalgal biomass for further processing. Using inorganic chemicals, high flocculation efficiency could be obtained within less time but the flocculants could not be separated from the medium, which would lead to water pollution. Chitosan could be used at low doses, but the price of this polymer was found to be prohibitive for large-scale operations. Among the three techniques studied at field level, $\mathrm{pH}$-induced flocculation by $\mathrm{NaOH}$ emerged to be efficient, costeffective and eco-friendly as the supernatant could be reused as growth medium by re-supplementing with essential nutrients and adjusting the $\mathrm{pH}$.

\section{Acknowledgements}

Financial support from Indian Council of Agricultural Research, New Delhi, India, and the research facilities provided by Indian Institute of Technology Kharagpur, India, are thankfully acknowledged. The first author wishes to acknowledge Miss Reeza Patnaik and Mr Sashi Sonkar, Ph.D. Scholars, Indian Institute of Technology Kharagpur, for helping in preparation of the manuscript.

\section{References}

1 J. R. Benemann, J. C. Weissman, B. L. Koopman and W. J. Oswald, Nature, 1977, 268, 19-23.

2 S. Sawayama, T. Minowa and S. Y. Yokoyama, Biomass Bioenergy, 1999, 17, 33-39.

3 E. M. Grima, E. H. Belarbi, F. G. A. Fernandez, A. R. Medina and Y. Chisti, Biotechnol. Adv., 2003, 20, 491-515.

4 Y. H. M. Li, N. Wu and C. D. C. N. Lan, Biotechnol. Prog., 2008, 24, 815-820.

5 B. Wang, Y. Li, N. Wu and C. Lan, Appl. Microbiol. Biotechnol., 2008, 79, 707-718.

6 E. W. Becker, Microalgae Biotechnology \& Microbiology, Cambridge University Press, 1994, pp. 56-62.

7 L. Christenson and R. Sims, Biotechnol. Adv., 2011, 29, 686702.

8 A. Papazi, P. Makridis and P. Divanach, J. Appl. Phycol., 2010, 22, 349-355.

9 J. Morales, J. De la Noue and G. Picard, Aquacultural Engineering, 1985, 4, 57-70.

10 A. Lavoie and J. Noüe de la, J. World Maric. Soc., 2009, 14, 685-694.

11 D. Vandamme, I. Foubert, B. Meesschaert and K. Muylaert, J. Appl. Phycol., 2010, 22, 525-530. 
12 S. Salim, R. Bosma, M. H. Vermuë and R. H. Wijffels, J. Appl. Phycol., 2011, 23, 849-855.

13 R. Misra, A. Guldhe, P. Singh, I. Rawat, T. A. Stenstrom and B. Faizal, Bioresour. Technol., 2015, 176, 1-7.

14 C. Y. Chen, K. L. Yeh, R. Aisyah, D. J. Lee and J. S. Chang, Bioresour. Technol., 2011, 102, 71-81.

15 J. C. Soeder and A. Bolze, Physiol. Plant., 1981, 52, 233-238.

16 T. Chatsungnoen and Y. Chisti, Algal Res., 2016, 13, 271-283.

17 J. M. S Rocha, J. E. C. Garcia and M. H. F. Henriques, Biomol. Eng., 2003, 20, 237-242.

18 S. Gao, M. Du, J. Tian, J. Yang, F. Ma and J. Nan, J. Hazard. Mater., 2010, 182, 827-834.

19 E. G. Bligh and W. J. Dyer, Can. J. Biochem. Physiol., 1959, 37, 911-917.

20 S. Mandal and N. Mallick, Appl. Microbiol. Biotechnol., 2009, 84, 281-291.

21 D. J. Nicholas and A. Nason, Methods in Enzymology III, Academic Press, New York, 1957, pp. 961-984.

22 American Public Health Association (APHA), Standard methods for the examination of water and waste water, Washington DC, USA, 20th edn, 1998, p. 1220.

23 Z. Wu, Y. Zhu, W. Huang, C. Zhang, T. Li, Y. Zhang and A. Li, Bioresour. Technol., 2012, 110, 496-502.

24 G. E. M. Molina, E. H. Belarbi and A. F. G. Fernandez, Biotechnol. Adv., 2003, 20, 491-515.

25 G. A. Parks, Equilibrium concepts in natural water systems, Advances in Chemistry Series, American Chemistry Society, Washington, DC, 1967, p. 67.
26 L. Chen, C. Wang, W. Wang and J. Wei, Bioresour. Technol., 2013, 133, 9-15.

27 N. B. Wyatt, L. M. Gloe, P. V. Brady, J. C. Hewson, A. M. Grillet, M. G. Hankins and P. I. Pohl, Biotechnol. Bioeng., 2012, 109, 493-501.

28 B. Pawlak and J. Kopeć, Oceanologia, 1998, 40, 345-353.

29 D. Vandamme, I. Foubert, I. Fraeye and K. Muylaert, Bioresour. Technol., 2012, 124, 508-511.

30 V. M. Rwehumbiza, R. Harrison and L. Thomsen, Chem. Eng. J., 2012, 200/202, 168-175.

31 N. Uduman, Y. Qi, M. K. Danquah, G. M. Forde and A. Hoadley, J. Renewable Sustainable Energy, 2010, 2, 012701.

32 Y. Xu, S. Purton and F. Baganz, Bioresour. Technol., 2013, 129, 296-301.

33 B. Koopman and E. P. Lincoln, Agric. Wastes, 1983, 5, 231246.

34 X. Zhang, P. Amendola, J. C. Hewson, M. Sommerfeld and Q. Hu, Bioresour. Technol., 2012, 116, 477-484.

35 W. Zhou, L. Gao, W. Cheng, L. Chen, J. Wang, H. Wang, W. Zhang and T. Liu, Algal Res., 2016, 18, 7-14.

36 J. E. Coons, D. M. Kalb, T. Dale and B. L. Marrone, Algal Res., 2014, 6, 250-270.

37 K. Pirwitz, L. R. Struckmann and K. Sundmacher, Bioresour. Technol., 2015, 196, 145-152.

38 J. Liu, Y. Tao, J. Wu, Yi. Zhu, B. Gao, Y. Tang and A. Li, Bioresour. Technol., 2014, 167, 367-375.

39 D. G. Kim, H. J. La, C. Y. Ahn, Y. H. Park and H. M. Oh, Bioresour. Technol., 2011, 102, 3163-3168. 